\title{
SOCIOPSIHOLOŠKA ANALIZA INGLHARTOVOG KONCEPTA VREDNOSTI SAMOIZRAŽAVANJA
}

\section{Zoran Pavlović1}

Institut društvenih nauka, Beograd

\begin{abstract}
Predmet rada jeste teorijska analiza dimenzije vrednosti preživljavanja/samoizražavanja koja je, u Inglhartovoj teoriji, shvaćena kao sindrom koji uključuje (post)materijalističke vrednosti, subjektivno blagostanje, interpersonalno poverenje, politički aktivizam i toleranciju manjinskih grupa. Na osnovu uobičajenog shvatanja prirode vrednosti u sociopsihološkoj literaturi, analizira se opravdanost takvog konceptualnog statusa predloženog sindroma $i$ njegovih elemenata kao dispozicija pojedinca. Analiza definisanja predloženog sindroma i njegove operacionalizacije, kao $i$ adekvatnosti posmatranja vrednosti kao odraza glavnih nezadovoljenih potreba pojedinca, ukazuje na nužnost revidiranja konceptualnog statusa pojma.
\end{abstract}

Ključne reči: vrednosti, vrednosti preživljavanja/samoizražavanja, revidirana teorija modernizacije

\footnotetext{
${ }^{1}$ Adresa autora: pavlozoran@gmail.com. Ovaj rad je deo projekta "Demokratski modeli unapređivanja društvene kohezije, tolerancije, ljudskih prava i privrednog razvitka u političkim i institucionalnim procesima evropskih integracija Srbije" (149017) koji finansira Ministarstvo za nauku i tehnološki razvoj Republike Srbije.
} 


\section{Uvod}

Koncept koji će biti predmet ovog rada relativno je nov u literaturi o vrednostima, političkoj kulturi, kao i društvenim naukama uopšte. Pojavio se u poslednjih nekoliko godina kao rezultat višegodišnjeg naučnog rada američkog sociologa Ronalda Inglharta i rezultat je empirijske analize podataka dobijenih u Svetskoj studiji vrednosti. Vrednosti samoizražavanja postale su jedan od ključnih elemenata kros-kulturnih istraživanja koje svaka ozbiljna studija vrednosti i/ili političke kulture uzima u obzir, a sam Inglhart jedan od najcitiranijih, ali i najosporavanijih autora u ovoj oblasti.

U ovom radu će biti analizirane slabosti shvatanja vrednosti u radovima pomenutog autora. Najpre će ukratko biti izloženo shvatanje o vrednostima saomoizražavanja, kao i teorija koja leži u osnovi ovog koncepta. Nakon toga će biti napravljen kritički osvrt na predloženi koncept u kontekstu relevantnih sociopsiholoških shvatanja prirode vrednosti kao dispozicija pojedinca, dok će u završnom delu biti prodiskutovane mogućnosti njegovog revidiranja.

\section{Priroda vrednosti samoizražavanja}

Od (post)materijalističkih vrednosti (Inglehart, 1971; 1990), preko (post)modernizma (Inglehart, 1997) do dimenzije vrednosti preživljavanja/samoizražavanja (eng. survival/self-expression values) i tzv. kulturne mape sveta (Inglehart, 2007; Inglehart \& Baker, 2000; Inglehart \& Welzel, 2005a), Inglhartove teorijsko-empirijske analize vrednosti temelje se na dve osnove: Maslovljevoj analizi hijerarhije potreba (Maslow, 1970) i teoriji modernizacije koja govori o grubo predvidljivim posledicama socioekonomskog razvoja na dominantne vrednosti određene zajednice (Inkeles, 1969; Inkeles \& Smith, 1974; Lerner, 1964; Smith \& Inkeles, 1966).

Vrednosni prioriteti pojedinca, prema Inglhartovom shvatanju, odražavaju socioekonomske uslove sredine, pri čemu se najveća subjektivna vrednost pridaje najvažnijim nezadovoljenim potrebama (tzv. hipoteza oskudice). Budući da su materijalne potrebe presudne za opstanak pojedinca, kada one nisu zadovoljene, uzimaju primat nad svim ostalim potrebama, uključujući i potrebe nematerijalnog tipa i obrnuto. Međutim, odnos materijalne oskudice i promene vrednosnih prioriteta nije trenutan jer vrednosti pojedinca, u najvećem stepenu, odražavaju uslove iz njegovih formativnih godina, $t j$. perioda rane socijalizacije, pa se vrednosti pre svega menjaju smenom generacija (tzv. hipoteza socijalizacije). Nakon dužeg perioda ekonomske i fizičke sigurnosti, mogu se očekivati značajne razlike između vrednosnih prioriteta mlađih i starijih 
grupa usled značajno različitih formativnih iskustava socijalizacije, što u perspektivi vodi promenama dominantnih vrednosti na nivou populacije.

U početku je suštinski koncept Inglhartove teorije bila dimenzija (post)materijalističkih vrednosti čije je širenje u populacijama razvijenih demokratskih zemalja tumačeno kao posledica dugoročnog ekonomskog razvoja u ovim sredinama nakon Drugog svetskog rata, koji je doveo do prosperiteta u kojima su odrastale mlade generacije koje su, samim tim, bile postmaterijalistički orijentisane (Inglehart, 1971; 1990). Međutim, od sredine devedesetih godina XX veka, dolazi do pomeranja teorijskog fokusa u radovima ovog autora i razvijanja teze o dve dimenzije kros-kulturnih varijacija, odnosno, posebno detaljnoj analizi jedne od njih, dimenzije vrednosti preživljavanja/samoizražavanja.

Za razliku od klasičnih teoretičara koji su modernizaciju posmatrali kao manje-više uniforman i pre svega linearan proces, modernizacija se, prema Inglhartovoj revidiranoj teoriji modernizacije, odvija kroz dve glavne faze - industrijsku i postindustrijsku - od kojih svaka sa sobom nosi promene u preovlađujućim pogledima na svet. Industrijska revolucija bila je povezana sa pomakom od tradicionalnih ka sekularno-racionalnim vrednostima, noseći sa sobom birokratizaciju, centralizaciju, standardizaciju i sekularizaciju autoriteta. Ovaj pomak, prema Inglhartu, ne predstavlja kritičko preispitivanje, već samo pomeranje osnove autoriteta od tradicionalno-religioznih ka sekularnoracionalnim izvorima (Inglhart \& Welzel, 2005a). Javljaju se materijalističke ideologije koje nude sekularne interpretacije istorije i utopije, ali su jednako dogmatske kao i religija, odražavajući rigidno disciplinovane i standardizovane načine na koje je organizovano industrijsko društvo, rad i život uopšte.

Pojava postindustrijskog društva dovodi do promene u drugom pravcu. Ekonomski rast i država blagostanja uvećavaju standard stanovništva do te mere da se zadovoljavanje materijalnih potreba može uzeti „zdravo za gotovo“. Rastući nivoi obrazovanja, širenje masovnih komunikacija i rad sa ljudima, simbolima i informacijama gde ljudi pre "misle nego što rade“ (Fukujama, 2002, str. 116) uvećavaju intelektualne veštine ljudi, dok rastuća socijalna kompleksnost, destandardizacija ekonomskih aktivnosti, ali i društvenog života uopšte, širi i diversifikuje ljudske socijalne mogućnosti. Sve to vodi materijalnoj, intelektualnoj i socijalnoj autonomiji pojedinca, što za posledicu ima preispitivanje nekontrolisanog i neograničenog autoriteta nad ljudima i osetljivost za ideje individualne slobode i jednakosti, tj. rastuću emancipaciju kako od religijskih, tako i od sekularno-racionalnih autoriteta.

Izuzev zajedničke tendencije uvećanja egzistencijalne sigurnosti, industrijska i postindustrijska faza modernizacije suštinski se razlikuju u vezi sa stepenom 
razvijanja individualne autonomije. Iako obe promene dovode do preoblikovanja orijentacija prema autoritetu, ,industrijska faza modernizacije donosi sa sobom sekularizaciju autoriteta, dok postindustrijska faza dovodi do emancipacije od autoriteta" (Inglehart \& Welzel, 2005a, str. 25). Ovaj proces odražava svojevrsnu humanističku transformaciju modernizacije budući da rastuće prihvatanje vrednosti samoizražavanja postaje ključna kulturna manifestacija modernizacije. Ljudska sloboda izbora i emancipacija postaju vodeće teme u svim oblastima života, od politike do vaspitanja dece, radne motivacije, religijskih orijentacija, građanskog angažovanja i sl.

Sve to ima jednu izuzetno važnu društvenu posledicu - rastuće zahteve za efektivnim građanskim i političkim slobodama i demokratskim institucijama u društvu, tamo gde one ranije nisu postojale, odnosno jačanjem demokratskih institucija tamo gde one već postoje. U postindustrijskom društvu socioekonomski razvoj, vrednosti samoizražavanja i efektivna demokratija čine celinu, obezbeđujući sredstva, vrednosti i prava koja ljude čine sposobnim, voljnim i posvećenim oblikovanju sopstvenih života u skladu sa sopstvenim autonomnim izborima. Ovaj proces, po mišljenju Inglharta, čini suštinsku karakteristiku ljudskog razvoja jer naglašava najdistinktivnije svojstvo čoveka: sposobnost da donosi odluke i ponaša se u skladu sa ličnim autonomnim izborima.

$\mathrm{Na}$ osnovu podataka iz četiri talasa Svetske studije vrednosti u kojima je učestvovalo preko 70 zemalja u svetu (ukupno blizu 200 istraživanja), odnosno preko 250000 ispitanika, Inglhart identifikuje dve dimenzije kros-kulturnih varijacija, tradicionalno/sekularno-racionalne vrednosti i vrednosti preživljavanja/samoizražavanja, koje predstavljaju ishode dve faze modernizacije. Dva dobijena faktora poslužili su kao osnova za konstruisanje poznate kulturne mape sveta (Baker, 2005; Inglehart, 1997; 2007; Inglehart \& Baker, 2000, Inglehart \& Welzel, 2005a).

U nekim od najranijih radova u kojima se detaljnija pažnja posvećuje ovom konceptu, dimenzija preživljavanje/samoizražavanje opisana je kao „sindrom poverenja, tolerancije, subjektivnog blagostanja, političkog aktivizma $i$ samoizražavanja koji se pojavljuje u postindustrijskim vrednostima koje karakteriše visok nivo sigurnosti“ (Inglehart \& Baker, 2000, str. 25) ili kao „klaster varijabli koji uključuje materijalističke nasuprot postmaterijalističkim vrednostima, subjektivno blagostanje, interpersonalno poverenje, politički aktivizam i toleranciju manjinskih grupa" (Inglehart \& Baker, 2000, str. 29). U nekim kasnijim radovima dimenzija je definisana kao „sindrom masovno prihvaćenih stavova u čijoj osnovi leži jedna dimenzija koja odražava naglašavanje slobode, toleranciju različitosti i participaciju“ (Inglehart \& Welzel, 2005b, str. 67), ali i kao dimenzija koja obuhvata „širok spektar uverenja $i$ vrednosti, koja odraža- 
vaju međugeneracijski pomak od naglašavanja ekonomske i fizičke sigurnosti pre svega, ka rastućem naglašavanju samoizražavanja, subjektivnog blagostanja i kvaliteta života" (Inglehart, 2007, str. 12).

U skladu sa ovim deskriptivnim definicijama, vrednosti samoizražavanja su operacionalizovane preko pet elemenata u koje spadaju sloboda i participacija (preferencija postmaterijalističkih ciljeva daljeg društvenog razvoja), javno samoizražavanje (spremnost za potpisivanje peticije), tolerancija različitosti ((ne)opravdavanje homoseksualnosti), subjektivno blagostanje (procena stepena lične sreće) i interpersonalno poverenje (uverenje da se većini ljudi može verovati). Struktura dimenzije i njen sadržaj prikazani su u tabeli br. 1.

Tabela 1. Faktorska struktura vrednosti preživljavanja/samoizražavanja na individualnom $i$ agregatnom nivou

\begin{tabular}{|c|c|c|}
\hline \multirow[b]{2}{*}{ Tvrdnje } & \multicolumn{2}{|c|}{ Faktorska zasićenja } \\
\hline & $\begin{array}{l}\text { Agregatni } \\
\text { nivo }\end{array}$ & $\begin{array}{l}\text { Individual- } \\
\text { ni nivo }\end{array}$ \\
\hline $\begin{array}{l}\text { Ispitanik prioritet daje ekonomskoj i fizičkoj sigurnos- } \\
\text { ti nasuprot samoizražavanju i kvalitetu života }\end{array}$ & .87 & .59 \\
\hline Ispitanik opisuje sebe kao ne baš srećnu osobu & .81 & .59 \\
\hline Homoseksualnost se nikada ne može opravdati & .77 & .58 \\
\hline Ispitanik nikada nije i nikada ne bi potpisao peticiju & .74 & .54 \\
\hline Treba biti oprezan kada se veruje drugim ljudima & .46 & .44 \\
\hline Procenat objašnjene varijanse & $\mathbf{2 5} \%$ & $13 \%$ \\
\hline
\end{tabular}

Izvor: Adaptirano prema Inglehart \& Welzel, 2005a, str.49 - 51.

Identična struktura dimenzije pojavljuje se i na individualnom i na agregatnom nivou analize (država kao jedinica analize), na podacima zasnovanim na drugačijim mernim postupcima, tipovima uzorka i drugim vremenskim periodima (Inglehart, 2007).

Analiza dobijene dimenzije potvrđuje neke od osnovnih pretpostavki Ingleharta na kojima je ovaj koncept zasnovan. Na intenzitet raširenosti vrednosti samoizražavanja intenzivno utiče nivo socioekonomskog razvoja društva (Inglehart \& Welzel, 2005a). Ove vrednosti su, sa druge strane, povezane sa širokim spektrom drugih stavova i vrednosti (Inglehart \& Baker, 2000; Inglehart, 2007) i, što je posebno važno, visoko koreliraju sa merama drugih srodnih koncepata sa kojima postoje teorijske sličnosti poput individualizmakolektivizma o kome govori Hofštede (Hofstede, 1980) ili Švarcove dimenzije autonomija-ukorenjenost (Schwartz, 2007). Najzad, stepen raširenosti vrednosti samoizražavanja unutar jednog društva visoko korelira sa kvalitetom demokratskih institucija i, zajedno sa ekonomskim indikatorima, objašnjava 
oko $80 \%$ varijanse razlika u stepenu demokratičnosti ${ }^{2}$ različitih zemalja (Inglehart, 2005). Ova impresivna povezanost navela je Inglharta na zaključak da je "veoma verovatno da će se demokratija pojaviti tamo gde više od $45 \%$ građana jednog društva karakterišu vrednosti samoizražavanja" (Inglehart \& Welzel, 2005a, str. 300). Vrednosti samoizražavanja na taj način postaju centralni aspekt Inglhartove teorije koja u njima vidi suštinu demokratske političke kulture i demokratskog potencijala pojedinca, a samu demokratiju shvata kao institucionalni odraz emancipativnih sila inherentnih ljudskom razvoju.

\section{Kritički osvrt na koncept vrednosti samoizražavanja}

Ukoliko bi se shvatanje o vrednostima samoizražavanja izneseno na prethodnim stranama ukratko sumiralo, u pitanju je jedna dimenzija koja obuhvata navedene elemente, karakteriše dobrostojeće nacije i pojedince i predstavlja odraz dominantnih nezadovoljenih potreba. Međutim, takvo shvatanje vrednosti kao dispozicija pojedinca ima neke očigledne slabosti. $U$ fokusu analize biće definisanje i operacionalizacija koncepta, kao i njegovo zasnivanje na dominantnim nezadovoljenim potrebama.

Definisanje koncepta vrednosti koji je predmet empirijskog istraživanja predstavlja prvi korak u istraživačkom procesu budući da formalno određenje, pre svega, utiče na izbor indikatora i način operacionalizacije vrednosti. Da li su vrednosti shvaćene kao subjektivne ili objektivne kategorije, lično i socijalno ili lično ili socijalno poželjne, kao uverenja, objekti neke potrebe, akcije ili svrhe, opšte ili specifične dispozicije itd., od presudne je važnosti za dalju analizu. Ako unapred nije jasno šta se meri, nemoguće je reći da li je to ono što je na kraju izmereno.

Obimna sociopsihološka literatura o vrednostima ukazuje na odsustvo konsenzusa o suštini ovog pojma. Neke analize pokazuju da postoji preko četiristo definicija vrednosti i čak osamnaest kriterijuma sa kojima se autori suočavaju pokušavajući da odrede sadržaj ovog pojma (Pantić, 2005). Konceptualna heterogenost i neujednačenost metodoloških standarda čini sadržaj pojma vrednosti i njegove osnovne karakteristike, a samim tim i način njegovog ispitivanja, u velikoj meri zavisnim ne samo od različitog shvatanja vrednosti unutar različitih disciplina (filozofska, kulturno-antropološka, sociološka, psihološka shvatanja vrednosti), već i od priklanjanja teorijskom stanovištu određenog

\footnotetext{
${ }^{2}$ Stepen "demokratičnosti" određenog društva odnosi se na pojam efektivne demokratije koji predstavlja indeks konstruisan na osnovu procena koje daju Fridom Haus (eng. Freedom House) i Transparensi Internešnel (eng. Transparency International).
} 
autora i konkretne definicije pojma vrednosti. Različiti autori koriste različite termine (vrednosti, vrednosne orijentacije, preferirani životni stilovi, idejne orijentacije i sl.), pridaju vrednostima različit konceptualni status (stav, bazični stavovi, bazične dimenzije socijalnog ponašanja, ali i crte ličnosti, motivi i sl.) i ispituju ih na različite načine (pitanjima sa više alternativa, nezavisnim ispitivanjem pojedinačnih vrednosti putem jednog ili više indikatora, ispitivanjem preferiranih životnih stilova, društvenih ciljeva i sl.).

Međutim, već i površan pregled dostupnih definicija vrednosti, ukazuje da se može govoriti o određenim zajedničkim karakteristikama shvatanja vrednosti u određenjima ovog pojma od strane različitih autora. Prema nekim autorima (Jagodzinski, 2004; Bilsky \& Schwartz, 1994; Schwartz \& Bilsky, 1987), može se govoriti o zajedničkim (formalnim) karakteristikama vrednosti u teorijskim određenjima različitih autora koje bi mogle biti shvaćene i kao imanentne odrednice vrednosti.

Vrednosti su, najpre, koncepti ili uverenja. U pitanju je preskriptivno ili proskriptivno uverenje (Rokeach, 1976) i predstavlja procenu nekog sredstva ili krajnjeg cilja akcije kao (ne)poželjnog. Ovu karakteristiku uključuju definicije brojnih domaćih i inostranih autora (npr. Kluckhohn, 1951; Kuzmanović, 1995; Rokeach, 1973; Schwartz \& Bardi, 2001).

Druga karakteristika sastoji se u shvatanju prema kome se vrednosti odnose na poželjne ciljeve, krajnja stanja ili ponašanje. Poželjnost je nezaobilazna i verovatno jedna od najdistinktivnijih karakteristika vrednosti. Mnogi autori pominju ovu karakteristiku ističući da su vrednosti preferencije načina života, koncepcije o poželjnom, poželjni ciljevi i sl. (Hofstede, 1980; Kluckhohn, 1951; Kuzmanović, 1995; Morris, 1956; Pantić, 1981; 1990; Rokeach, 1973).

Vrednosti prevazilaze specifične situacije. Ova odrednica vrednosti je u velikom broju teorijskih određenja prisutna u vidu isticanja opštosti vrednosti, tačnije, isticanja različitih nivoa opštosti različitih vrednosti (Kuzmanović, 1995; Kluckhohn, 1951; Pantić, 1981; 1990). Kada se u okviru sociopsihološke problematike razmatraju vrednosti, onda su uvek u pitanju opšte vrednosti koje predstavljaju odnos prema društveno relevantnim pojavama i često se nazivaju socijalnim vrednostima, koje determinišu širok opseg socijalnog ponašanja (Rot, 1994). Različiti nivoi opštosti pojedinih vrednosti impliciraju i hijerarhijsko ustrojstvo, ali u smislu principa organizovanja, a ne večitog i univerzalnog redosleda vrednosti.

Vrednosti upravljaju selekcijom ili evaluacijom ponašanja, ljudi i događaja, što je posledica centralnosti dispozicije u strukturi ličnosti čoveka koja ga intenzivno i kontinuirano pokreće na određene aktivnosti. Vrednosti vode zauzima- 
nju određenih pozicija u pogledu društvenih tema ili prihvatanje određene političke ili religijske ideologije nasuprot drugoj (Rokeach, 1973), imaju uticaj na izbor dostupnih načina, sredstava i ciljeva akcije (Kluckhohn, 1951), postavljanje kriterijuma pomoću kojih ljudi ranguju svoje intenzitete želja (Catton, 1954), kriterijuma za preferenciju (Williams, 1969) ili usmeravanje ponašanja (Pantić, 1981; 1990).

Najzad, vrednosti karakteriše relativna stabilnost (mada se ona implicitno podrazumeva isticanjem transsituacionog karaktera vrednosti). Bilo da se posmatra kao standard koji perzistira (Catton, 1954), stabilna dispozicija (Barton, 1963), trajno uverenje (Rokeach, 1973), trajni odnos (Rot i Havelka, 1973) ili relativno stabilna dispozicija (Pantić, 1981; 1990), vrednosti se posmatraju kao duboko ukorenjene i teško promenljive karakteristike pojedinca koje ponašanju daju doslednost i konzistentnost. Vrednosti nisu nepromenljive ili potpuno stabilne (kada nikakva lična $\mathrm{i} / \mathrm{ili}$ društvena promena ne bi bila moguća), ali ni potpuno nestabilne i lako promenljive (čime bi bilo kakav kontinuitet $\mathrm{u}$ razvoju bio onemogućen) (Rokeach, 1973).

Izložena analiza suštinskih odrednica vrednosti u sociopsihološkoj literaturi je sa stanovišta ovog rada od presudne važnosti jer je jedna od glavnih slabosti Inglhartove teorije odsustvo eksplicitno definisanog shvatanja prirode vrednosti. Nema formalne definicije vrednosti ni konceptualnog razgraničenja od drugih srodnih pojmova; izostaje teorijska analiza prirode ovog pojma, mogućnosti njegove operacionalizacije; eventualno pozivanje na istaknute autore $u$ ovoj oblasti (Rokič je jedan od retkih na koje se Inglhart poziva) ili preuzimanje njihovog stanovišta i sl. U najboljem slučaju govori se o funkciji vrednosti koje „postavljaju standarde za poželjne i nepoželjne ciljeve ... što ih čini moćnim motivacionim regulatorom ljudskog ponašanja“ (Inglehart \& Welzel, 2005a, str. 23).

Odsustvo formalne definicije vrednosti u ovom slučaju predstavlja posebnu teškoću budući da ni centralni koncept Inglhartove teorije, vrednosti samoizražavanja, nije definisan na odgovarajući način. Sva gorenavedena određenja vrednosti samoizražavanja predstavljaju deskriptivne definicije - određenje koncepta nabrajanjem elemenata koji čine analizirani skup indikatora. To je vrlo nizak nivo definisanja jer koncept nije definisan formalno, $\mathrm{tj}$. nezavisno od sadržaja, pa promena skupa indikatora (odnosno sadržaja) preko kojih je pojam definisan nužno nosi i promenu njegovog značenja ${ }^{3}$. Proces koji nije

\footnotetext{
${ }^{3}$ Brojne su i terminološke nejasnoće jer se za iste indikatore koriste različiti pojmovi koji jesu srodni, ali ne nužno i identični po svom značenju. Na primer, alternativno se upotrebljavaju pojmovi tolerancija/tolerancija različitosti/tolerancija manjinskih grupa ili politički aktivi-
} 
išao deduktivnim (od definisanja ka operacionalizaciji) već induktivnim putem (od uočenih dispozicija ka njihovom teorijskom objedinjavanju) uslovio je nekonzistentno definisanje pojma jer izbor indikatora i način njihove operacionalizacije nije bio uslovljen i omeđen prethodno postojećom definicijom. Drugim rečima, ,istraživanja koja nisu vođena konceptom strukture vrednosti moraju se oslanjati na pojedinačne vrednosti, arbitrarno izabrane od strane istraživača“" (Schwartz \& Bilsky, 1987, str. 551).

Poseban problem predstavlja Inglhartovo insistiranje da je svaki od pet elemenata sindroma vrednost za sebe, što se, između ostalog, vidi i u korišćenju množine kada se govori o vrednostima samoizražavanja. Međutim, nejasno je ne samo koje su to vrednosti koje najbolje reprezentuju sadržaj samoizražavanja (jer to nije unapred određeno, ni teorijski obrazloženo), nego se postavlja i pitanje koje su to vrednosti čiji indikatori jesu ovih pet elemenata. Osim (post)materijalističkih vrednosti, čije su značenje i struktura u Inglhartovim ranijim radovima jasno eksplicirani (Inglehart, 1990), i tolerancije prema homoseksualnosti koja bi mogla biti shvaćena kao indikator tolerancije, nejasno je koje vrednosti stoje u osnovi spremnosti za potpisivanje peticije, interpersonalnog poverenja i subjektivnog blagostanja.

Pretpostavka je da su to manifestacije težnja ka samoizražavanju, ali bi ovi elementi mogli biti indikatori širokog spektra vrednosnih orijentacija (ali i drugih dispozicija koje nisu vrednosti). Sam Inglhart tu nije do kraja jasan jer, prema izloženoj teoriji, u osnovi grupisanja indikatora u sindrom samoizražavanja leži težnja ka autonomnom donošenju odluka kao univerzalna potreba koja prevazilazi kulturne, civilizacijske ili bilo koje druge razlike. Nameću se dva jednostavna pitanja: zašto koncept nije tako i definisan (kao autonomija, individualizam, težnja ka autonomiji i sl.), odnosno, šta je zapravo glavna intrapsihička sila ili dominantan motiv - samoizražavanje ili težnja ka autonomiji? Iako su ova dva pojma u složenim odnosima međuzavisnosti, njihova značenja međusobno se ne iscrpljuju i ne mogu se svesti jedan na drugi. Dodatnu konfuziju unosi i činjenica da je samoizražavanje jedna od četiri funkcije stavova i vrednosti (Katz, 1960; Rot, 1994) i da, iako ova funkcija vrednosti može biti manje ili više izražena, sve vrednosti teže da se izraze, odnosno svaka vrednost predstavlja izražavanje ličnosti pojedinca, pa su u tom smislu sve vrednosti koje pojedinac poseduje u strukturi ličnosti barem u izvesnom stepenu vrednosti samoizražavanja. Iz Inglhartove analize nije jasno da li se o

zam/participacija/nekonvencionalne forme političke akcije, dok neke definicije sadrže elemente cirkularnosti, pa se vrednosti samoizražavanja definišu kao sindrom koji između ostalog uključuje i samoizražavanje. 
samoizražavanju govori kao o funkciji vrednosti (manje verovatno) ili određenoj vrsti vrednosti (verovatnije).

Otvoreno je i pitanje da li je lista od pet indikatora dovoljno iscrpan spisak za tako sveobuhvatnu i ultimativnu potrebu ljudi koja utiče na totalitet psihičkog dinamizma. Inglhart je prvobitno koristio širi spisak od jedanaest indikatora (Inglehart, 1997), ali je kasnije, zbog nedostajućih podataka za pojedine države, broj indikatora sveden na pet. Dva indeksa konstruisana na osnovu različitog broja varijabli visoko koreliraju $(r=0,96)$. Međutim, nije pokazano da je odgovarajuća kombinacija koja čini kraću verziju vrednosti samoizražavanja pouzdanija, validnija ili diskriminativnija, nego neka druga kombinacija varijabli od ukupnog spiska indikatora koji je prvobitno korišćen, a u odnosu na neki spoljni kriterijum ili relevantan koncept. Nikakva teorijska analiza nije prethodila proveri jednodimenzionalnosti izdvojenog skupa indikatora, koja je, sa druge strane, shvaćena kao ključni argument opravdanosti posmatranja ovog sindroma kao skupa indikatora vrednosti samoizražavanja. Međutim, upravo neke analize podataka na uzorku Srbije pokazuju da pretpostavka jednodimenzionalnosti ne može biti prihvaćena jer faktorska analiza pet navedenih indikatora otkriva dva faktora (Pavlović, 2009). Švarc opravdano navodi da je nepouzdano zaključivati o bazičnim vrednostima na osnovu odgovora na specifične stavove i da je nužno postaviti brojna pitanja u raznim oblastima sadržaja određene vrednosti (Schwartz, 2007). Stoga je, za ovog autora, značenje Inglhartovih dimenzija „izvedenih na osnovu zaključaka o korelacijama različitih ajtema, a ne a priori jasno definisanih i operacionalizovanih, nužno slabo" (Schwartz, 2007, str. 40). Najzad, većina analiziranih indikatora ima jasnu političku konotaciju, ali političko ponašanje ljudi, kao jedan uzak segment ukupnog socijalnog ponašanja pojedinca, nije nužno najbolji kanal ekspresije potrebe za samoizražavanjem (ukoliko se ne dokaže suprotno). Mnogo više smisla imalo bi govoriti o političkom samoizražavanju ili vrednostima političkog samoizražavanja, naročito ukoliko se ima u vidu da je izbor indikatora, čini se, više bio vođen procentom objašnjene varijanse u efektivnosti demokratije nego unapred formulisanim teorijskim argumentima. U tom kontekstu je posebno važan podatak da Inglhart, i pored konstantnog insistiranja na prodemokratskom karakteru predloženog sindroma kako pojedinaca, tako i nacija u celini, nigde ne daje dokaze o povezanosti izraženosti vrednosti samoizražavanja sa drugim relevantnim karakteristikama pojedinca koji imaju jasno značenje i proverenu validnost. Iznanađujuće zapostavljen jeste, na primer, odnos samoizražavanja i autoritarnosti. Iako postoji očigledna razlika u fokusu između svojevrsne istorijski oblikovane kauzalnosti u slučaju tumačenja izvora vrednosti samoizražavanja koja nije inkompatibilna, ali je svakako različita od analize psihodinamike autoritarnosti, analiza odnosa ova dva fe- 
nomena bila bi od izuzetne važnosti, budući da su u pitanju dva koncepta koja, barem teorijski, imaju jasno suprotstavljena značenja.

Čak iako se uz sve navedene ograde prihvati lista indikatora, od pet elemenata vrednosti samoizražavanja, s obzirom na analizu suštinskih odrednica vrednosti kao koncepta u socijalnoj psihologiji, strože metodološke kriterijume i kriterijume operacionalizacije svakako zadovoljava prvi element sindroma, (post)materijalističke vrednosti, koje predstavljaju iskazanu preferenciju poželjnih, društveno relevantnih ciljeva, i, prema Inglhartu, zauzimaju centralnu poziciju u vrednosnom sistemu pojedinca i, samim tim, utiču na širok opseg drugih stavova i ponašanja. Međutim, dok se tolerancija i građanski aktivizam mogu u krajnjoj liniji smatrati indikatorima vrednosti, ako ne i vrednostima po sebi (pre svega zbog načina operacionalizacije), status interpersonalnog poverenja i subjektivnog blagostanja kao vrednosti krajnje je problematičan.

Nema sumnje da ovi elementi svakako mogu upućivati na određenu vrednost, tj. biti shvaćeni i kao indikatori samoizražavanja kao opštije vrednosti (ili neke druge vrednosti). Međutim, način na koji su ove dve dispozicije operacionalizovane, tj. merene, ostavlja, pre svega, otvoreno pitanje mogućnosti iskazivanja preferencije, odnosno poželjnosti određenih ciljeva, stanja ili načina ponašanja kao jedne od osnovnih karakteristika vrednosti. Stoga se nameće jednostavno pitanje: kakvu koncepciju (ne)poželjnog pojedinac iskazuje time što, recimo, izjavi da jeste ili nije srećan? Ovakav tretman subjektivnog blagostanja posebno iznenađuje ako se ima u vidu da je sam Inglhart subjektivno blagostanje iskazano preko procene stepena sreće posmatrao kao emocionalno stanje (Inglehart, 1990).

Konceptualni status subjektivnog blagostanja i interpersonalnog poverenja mnogo je bliži nekim drugim pojmovima, poput crte ličnosti ili tzv. socijalnog aksioma, tj. osnovne premise $u$ formi uopštenog očekivanja koju ljudi koriste kao princip ponašanja u svakodnevnom životu, različit od vrednosti, jer nije nužno poželjan koncept (Bond et al., 2004; Szakolczai \& Fustos, 1998). Nije neuobičajeno da se određene crte ličnosti posmatraju istovremeno i kao vrednosti, pre svega instrumentalne (Kuzmanović, 1995; Rokeach, 1973; Pantić, 1981; 1990). Takođe, nije neuobičajeno da se, na primer, sreća posmatra kao (terminalna) vrednost (Rokeach, 1973; Schwartz \& Bilsky, 1987). Međutim, način operacionalizacije interpersonalnog poverenja i subjektivnog blagostanja koji koristi Inglhart više se odnosi na (samo)deskripcije obrazaca ponašanja, nego na kriterijume koje pojedinci koriste u proceni poželjnosti ponašanja, ljudi i događaja. Takođe, ova dispozicija pre može biti posmatrana u terminima stepena u kojima je pojedinci manifestuju ili poseduju, a ne kao karakteristika koja varira u značaju koji pojedinci pripisuju određenim ciljevima. 
Najzad, pre bi se reklo da subjektivno blagostanje i interpersonalno poverenje opisuju postupke ljudi uzrokovane time kakvi oni stvarno jesu, bez obzira na njihove namere, dok se vrednosti odnose, pre svega, na ciljeve pojedinaca. Drugim rečima, način na koji su ovi indikatori operacionalizovani dozvoljava mogućnost ispitivanja faktičkog postojanja određene karakteristike pojedinca, a ne njenog pozitivnog vrednovanja (bez obzira koliko je pojedinac stvarno poseduje) (Kuzmanović, 1995).

Ovaj prigovor odnosi se kako na dva navedena elementa, tako i na Inglhartovu tvrdnju da je vrednost činjenica da ispitanik jeste ili bi potpisao peticiju, odnosno da smatra da se homoseksualnost (ne) može opravdati. Drugim rečima, izuzev (post)materijalističkih vrednosti koje nisu bez svojih mana (Clarke \& Dutt, 1991; Dutch \& Taylor, 1993), svi ostali elementi ne samo da ne zadovoljavaju barem jedan od formalnih uslova - ne odnose se na poželjne ciljeve, stanja ili ponašanje - nego je za neke uslove nemoguće reći da li su zadovoljeni. Nemoguće je, recimo, proceniti stabilnost karakteristika poput interpersonalnog poverenja, motivacioni potencijal subjektivnog doživljaja sreće ili opštost spremnosti za potpisivanje peticije budući da je za takve zaključke potrebna odgovarajuća teorijsko-empirijska analiza koju Inglhartova teorija ne pruža.

Najzad, prigovor načelne prirode može se uputiti shvatanju prema kome su vrednosni prioriteti pojedinca isključivo odraz glavnih nezadovoljenih potreba jer bi se onda, ako su potrebe i vrednosti ekvivalentni pojmovi, i za „pacova, $u$ stepenu u kome se može reći da on ima potrebe, moglo takođe reći da u istom stepenu poseduje i vrednosti“" (Rokeach, 1973, str. 20). Ne može se generalizovati i reći da ako pojedinac nešto nisko ranguje, to čini zbog toga što to već poseduje ili, obrnuto, da nečemu teži jer mu je nedostupno. Postoji nekoliko razloga zbog kojih određena vrednost može biti rangirana nisko ili visoko (Rokeach, 1973). Osoba može visoko vrednovati nešto jer želi ono što nema (što je, u principu, Inglhartovo gledište) ili zato što to ima, ali ga želi još više. Sa druge strane, osoba može nešto vrednovati nisko jer još nije dovoljno zrela da to ceni, zato što to već ima i uzima ga zdravo za gotovo ili zato što to niti ima, niti želi. Na izbor ciljeva utiču kako vlastite potrebe, tako i interesi drugih ljudi, životna filozofija, pogled na svet, aktuelni egzistencijalni položaj, društvena situacija (Kuzmanović, 1995), tj. veći broj međuzavisnih faktora koji su u teoriji Inglharta potpuno zanemareni. Time ovo shvatanje predstavlja paradigmatski primer materijalističke teorije koja implicira direktnu uslovljenost ideja materijalnim okolnostima, čime se, između ostalog, potpuno zanemaruje bilo kakva značajnija uloga samog pojedinca, tj. individualnih činilaca formiranja i održanja vrednosti, iako sam pojam vrednosti omogućuje da se čovek 
posmatra kao „aktivno, samosvesno i prema određenim ciljevima i idealima usmereno biće" (Pantić, 1981, str. 10), a ne samo kao pasivan objekt manipulacije sredinskih sila.

\section{Zaključak}

Deskriptivno i nekonzistentno definisanje vrednosti preživljavanja/samoizražavanja, manje-više proizvoljan izbor indikatora njihove operacionalizacije i njihovo isključivo zasnivanje na glavnim nezadovoljenim potrebama dovodi u sumnju opravdanost tretiranja predloženog sindroma kao vrednosti u sociopsihološkom smislu. Svi predloženi elementi sindroma svakako ne zadovoljavaju ozbiljnije metodološke kriterijume i kriterijume operacionalizacije budući da, ne samo da nisu jasno razgraničeni od nekih drugih srodnih koncepata, nego samo značenje pojedinih elemenata nije jasno. Čini se da neki autori, s pravom koriste znake navoda kada govore o samoizražavanju, upućujući da su to, u Inglhartovoj teoriji, vrednosti samo uslovno (Bond, 2004) ili su krajnje kritični prema takvom statusu vrednosti samoizražavanja, smatrajući ih heterogenom skupinom ajtema (Haller, 2002).

Redefinisanje koncepta koje se čini nužnim moglo bi ići u jednom od dva moguća smera, pri čemu je od presudne važnosti razlikovanje individualnog i agregatnog nivoa analize. U analizi vrednosti samoizražavanja kao karakteristika pojedinca, tj. na individualnom nivou, nužna je detaljnija teorijskoempirijska analiza i provera predloženog sindroma, pre svega analiza uticaja sociodemografskih varijabli koje se u teoriji smatraju presudnim, kao i analiza povezanosti sa drugim relevantnim psihološko-dispozicionim varijablama. Iako teorija postulira raširenost vrednosti samoizražavanja u dobrostojećim delovima populacije jednog društva, odsutna je analiza distribucije vrednosti samoizražavanja među pojedinim grupama unutar populacije određenih zemalja, kao i analiza efekata ličnih primanja ili nivoa obrazovanja ispitanika na stepen prihvatanja ovih vrednosti (Berg-Schlosser, 2003). Time bi, između ostalog, i neke od fundamentalnih pretpostavki na kojima je koncept zasnovan mogle biti empirijski proverene (npr. hipoteza oskudice). Sa druge strane, analiza povezanosti vrednosti samoizražavanja sa drugim relevantnim sociopsihološkim konceptima, pre svega sa autoritarnošću, dala bi dragocene uvide o prirodi i sadržaju sindroma, pre svega s obzirom na pretpostavljeni prodemokratski karakter, ali i odgovorila na još jedno, važnije pitanje: da li analizirana dimenzija predstavlja distinktivno različit pojam od drugih srodnih koncepata ili predstavlja samo jednu varijantu već poznatih i široko primenjivanih kons- 
trukata. U protivnom, daleko više smisla ima „razgradnja“ sindroma, tj. analiza pojedinačnih elemenata (Muller \& Seligson, 1994).

Drugu mogućnost predstavlja analiza sindroma kao agregatnog fenomena, odnosno njegova prevashodna upotreba na agregatnom nivou analize. To, uostalom, i Inglhart čini govoreći o vrednostima samoizražavanja kao subjektivnom aspektu demokratske političke kulture. Na taj način bi vrednosti samoizražavanja mogle biti definisana kao sindrom strukturno shvaćene političke kulture (Almond \& Verba, 1960; Patrick, 1984; Pantić i Pavlović, 2009). Ako se ima u vidu jasna politička konotacija pojma i daleko detaljnije agregatne analize dostupne u radovima Inglharta, to se čini kao optimalno rešenje. Međutim, i u tom slučaju se ne može preuzeti neizmenjeni konceptualni status pojma jer vrednosti, iako najvažniji, nisu jedini element političke kulture, pa implicitno izjednačavanje dva pojma nije prihvatljivo. Dodatna mogućnost jeste posmatranje predloženog sindroma kao karakteristike kulture ili kulturnog sindroma, komponente globalne perspektive (Triandis, 1996).

Jasno razgraničenje dva nivoa analize moglo bi otkloniti neke očigledne teškoće u vezi sa predloženim konceptom, a u skladu sa dobro poznatom činjenicom u kros-kulturnim istraživanjima da se povezanosti i strukture određenog skupa varijabli registrovanih na agregatnom nivou ne reprodukuju nužno na individualnom nivou analize i obrnuto (Inglehart \& Welzel, 2005b). To je posebno važno ukoliko se ima u vidu da su najvažniji faktori varijacije pojedinih elemenata sindroma samoizražavanja (pre svega interpersonalnog poverenja i subjektivnog blagostanja) oni sa makro-nivoa čiji korelati ne mogu biti pronađeni na individualnoj ravni analize (Dekker, Ester, \& Vinken, 2003; Inglehart, 1990; Pavlović, 2009).

Najzad, da bi se uopšte moglo govoriti o vrednostima samoizražavanja, nužno je proširenje spiska indikatora $i$, pre svega, drugačija operacionalizacija varijabli koja bi omogućila analizu koncepcija poželjnih ciljeva, stanja i oblika ponašanja (što vrednosti po definiciji podrazumevaju), a ne faktičkog postojanja određenih karakteristika pojedinca. U protivnom, ne može se govoriti o vrednostima u konceptualnom smislu. 


\section{Literatura}

Almond, G., \& Verba, S. (1963). The civic culture. Newbury Park: Sage Publications.

Baker, W. (2005). America's crisis of values: Reality and perception. Princeton and Oxford: Princeton University Press.

Barton, A. (1963). Measuring the values of individuals. New York: Columbia University Press.

Berg-Schlosser, D. (2003). Comment on Welzel, Inglehart and Klingemann's 'The theory of human development: A cross-cultural analysis'. European Journal of Political Research, 42, 381-386.

Bilsky, W., \& Schwartz, S. H. (1994). Values and personality. European Journal of Personality, 8, 163-181.

Bond, M. H. (2004). Culture-level dimensions of social axioms and their correlates across 41 cultures. Journal of Cross-Cultural Psychology, 35, 548570.

Catton, W. R. (1954). Exploring techniques for measuring human values. American Sociological Review, 18, 49-55.

Clarke, H. D., \& Dutt, N. (1991). Measuring value change in Western industrialized societies: The impact of unemployment. American Political Science Review, 85, 905-920.

Dekker, P., Ester, P., \& Vinken, H. (2003). Civil society, social trust, and democratic involvement. U W. Arts, L. Halman and J. Hagenaars (Eds.). The cultural diversity of European unity (pp. 217-254). Leiden-Boston: Brill.

Duch, R. M., \& Taylor, M. A. (1993). Postmaterialism and the economic condition. American Journal of Political Science, 37, 747-779.

Fukujama, F. (2002). Kraj istorije i poslednji čovek. Podgorica: CID.

Haller, M. (2002). Theory and method in the comparative study of values: Critique and alternative to Inglehart. European Sociological Review, 18, 139158.

Hofestede, G. (1980). Culture's consequences: International differences in work-related values. London: Sade Publications.

Inglehart, R. (1971). The silent revolution in Europe: Intergenerational change in post-industrial societies. American Political Science Review, 65, 9911017.

Inglehart, R. (1990). Culture shift in advanced industrial societies. Princeton: Princeton University Press. 
Inglehart, R. (1997). Modernization and postmodernization: Cultural, economical, and political change in 43 societies. Princeton: Princeton University Press.

Inglehart, R. (2005). Democratization as the growth of freedom: The human development perspective. Japanese Journal of Political Science, 6, 1-31.

Inglehart, R. (2007). Mapping global values. U Y. Esmer \& T. Pettersson (Eds.). Measuring and mapping cultures: 25 years of comparative value surveys (pp. 11-32). Leiden-Boston: Brill.

Inglehart, R., \& Baker, W. E. (2000). Modernization, culture change and the persistence of traditional values. American Sociological Review, 65, 19-51.

Inglehart, R., \& Welzel, C. (2005a). Modernization, culture change, and democracy: The human development sequence. Cambridge: Cambridge University Press.

Inglehart, R. \& Welzel, C. (2005b). Political culture and democracy: Analyzing cross-level linkages. Comparative Politics, 36, 61-79.

Inkeles, A. (1969). Making man modern: On the causes and consequences of individual change in six developing countries. The American Journal of Sociology, 75, 208-225.

Inkeles, A., \& Smith, D. H. (1974). Becoming modern. London: Heinemann.

Jagodzinski, W. (2004). Methodological problems of value research. U H. Vinken, J. Soeters and P. Ester (Eds.). Comparing cultures: Dimensions of culture in a comparative perspective (pp. 97-121). Leiden: Brill.

Katz, D. (1960). The functional approach to the study of attitudes. Public Opinion Quarterly, 24, 163-204.

Kluckhohn, C. (1951). Values and value orientations in the theory of action. U T. Parsons \& E. Shils (Eds.). Toward a general theory of action (pp. 387433). New York: Harper\&Row.

Kuzmanović, B. (1995). Društvene promene i promene vrednosnih orijentacija učenika. Psihološka istraživanja, 7, 17-47.

Lerner, D. (1964). The passing of traditional society. New York: Free Press

Maslow, A. H. (1970). Motivation and personality. New York: Harper\&Row.

Morris, C. (1956). Varieties of human life. Chicago: University of Chicago Press.

Muller, E. M., \& Seligson, M. A. (1994). Civic culture and democracy: The question of causal relationships. American Political Science Review, 88, 635-652.

Pantić, D. (1981). Vrednosne orijentacije mladih u Srbiji. Beograd: Istraživačko-izdavački centar SSO Srbije. 
Pantić, D. (1990). Promene vrednosnih orijentacija mladih u Srbiji. Beograd: Institut društvenih nauka, Centar za politikološka istraživanja i javno mnjenje.

Pantić, D. (2005). Da li su vrednosti bivših komunističkih zemalja slične?. Zbornik Matice srpske za društvene nauke, 118-119, 49-69.

Pantić, D., \& Pavlović, Z. (2009). Political culture of voters in Serbia. Belgrade: Institute of Social Sciences.

Pavlović, Z. (2009). Vrednosti samoizražavanja u Srbiji: u potrazi za demokratskom političkom kulturom. Beograd: Institut društvenih nauka.

Patrick, G. M. (1984). Political culture. U G. Sartori (Ed.). Social science concepts (pp. 265-314). London: Sage.

Rokeach, M. (1973). The nature of human values. New York: The Free Press.

Rokeach, M. (1976). Beliefs, attitudes, and values. San Francisco: Jossey-Bass Publishers.

Rot, N. (1994). Osnovi socijalne psihologije. Beograd: Zavod za udžbenike i nastavna sredstva.

Rot, N., i Havelka, N. (1973). Nacionalna vezanost $i$ vrednosti kod srednjoškolske omladine. Beograd: Institut za psihologiju i Institut društvenih nauka.

Schwartz, S., \& Bilsky, W. (1987). Toward a universal psychological structure of human values. Journal of Personality and Social Psychology, 53, 550562.

Schwartz, S. H., \& Bardi, A. (2001). Value hierarchies across cultures: Taking a similarities perspective. Journal of Cross-Cultural Psychology, 32, 268290.

Schwartz, S. H. (2007). A theory of cultural value orientations: Explication and applications. U Y. Esmer \& T. Pettersson (Eds.). Measuring and mapping cultures: 25 years of comparative value surveys ( $p p$. 33-78). LeidenBoston: Brill.

Smith, D. H., \& Inkeles, A. (1966): The OM Scale: A Comparative SocioPsychological Measure of Individual Modernity. Sociomerty, 29, 353-377.

Szakolczai, A., \& Fustos, L. (1998). Value systems in axial moments: A comparative analysis of 24 European countries. European Sociological Review, 14, 211-229.

Triandis, H. C. (1996). The psychological measurement of cultural syndromes. American Psychologist, 51, 407-415.

Wiliams, R. (1969). Generic American values. U V. R. Rodgers (ed.). A sourcebookfor social sciences (pp. 133-141). London: Macmillan. 
APSTRACT

\section{SOCIOPSYCHOLOGICAL ANALYSIS OF INGLEHART'S CONCEPT OF SELF-EXPRESSION VALUES}

Zoran Pavlovic

The subject of this paper is theoretical analysis of the dimension of survival/self-expression values which, in Inglehart's theory, comprises (post)materialist values, subjective well-being, interpersonal trust, political activism and tolerance of minority groups. Based on the common understanding of the nature of values in sociopsychological literature, the adequacy of the conceptual status of this syndrome and its elements as individual values dispositions was analysed. The analysis of the definition of this syndrome and its operationalisation, as well as of adequacy of treating values as the expression of the main ungratified needs of an individual, suggests the necessity of revision of the conceptual status of this notion.

Key words: values, survival/self-expression values, revised theory of modernisation 